Aksaray University
Journal of Science and Engineering
e-ISSN: 2587-1277
http://dergipark.gov.tr/asujse
http://asujse.aksaray.edu.tr

Research Article

\title{
Investigation of The New Generation Detector System Using in Medical
} Image

\author{
Nuray Yavuzkanat ${ }^{1, \star}$, Sefa Erturk ${ }^{2}$ \\ ${ }^{1}$ Bitlis Eren University, Faculty of Arts and Science, Physics Department, Bitlis, 13000 Turkey \\ ${ }^{2}$ Niğde Ömer Halisdemir University, Faculty of Arts and Science, Physics Department, Niğde, 51240 Turkey
}

-Received Date: Nov 19, 2019

-Revised Date: Nov 29, 2019

-Accepted Date: Nov 30, 2019

•Published Online: Dec 04, 2019

\begin{abstract}
Mammography and standard breast imaging devices in the hospital are not enough an accurate diagnosis of breast cancer especially over the 40 years old and overweight women. The spatial resolution of the scintillation detector system is a highly important parameter for nuclear medical imaging. GATE simulation program, based on GEANT4, is used for the investigation of the SPECT system with different scintillations which are commonly used in the imaging device. Medical images for the point source are obtained by ImageJ software and image properties such as spatial resolution and mean grey values are compared for the several scintillations. This research shows that the spatial resolution value for GAGG(Ce), relatively new scintillation material, is very close to $\mathrm{SrI}$ which is one of the expensive scintillators. NaI, $\mathrm{LaBr}$ and $\mathrm{CeBr}$ are extremely hygroscopic and not easy to be packaging with a specific shape. Therefore, $\mathrm{GAGG}(\mathrm{Ce})$ are found to be encouraging result to be a part of the novel medical image device. This study also shows how important using collimator in front of the scintillation material for obtaining a meaningful image and how improved the image quality using the array scintillator instead of one single block. There is not any research regarding medical imaging obtained by GAGG(Ce) scintillation material in GEANT4 simulation, so this research data presented are the first of their kind.
\end{abstract}

\section{Keywords}

Scintillation, Spatial Resolution, GAGG(Ce), GATE Simulation, Medical Imaging.

^Corresponding Author: Nuray Yavuzkanat, nyavuzkanat@beu.edu.tr 


Aksaray University
Journal of Science and Engineering
e-ISSN: 2587-1277
http://dergipark.gov.tr/asujse
http://asujse.aksaray.edu.tr

Research Article

\title{
Medikal Görüntülemede Kullanılmak Üzere Araştırılan Yeni Nesil Gama Dedektör Sistemi
}

\author{
Nuray Yavuzkanat ${ }^{1, *}$, Sefa Ertürk ${ }^{2}$ \\ ${ }^{1}$ Bitlis Eren Üniversitesi, Fen Edebiyat Fakültesi, Fizik Bölümü, Bitlis, 68100, Türkiye \\ ${ }^{2}$ Niğde Ömer Halisdemir Üniversitesi, Fen Edebiyat Fakültesi, Fizik Bölümü, Niğde, 51240, Türkiye \\ -Gönderi Tarihi: 19 Kas $2019 \quad$-Düzeltme Tarihi: 29 Kas $2019 \quad$ •Kabul Tarihi: 30 Kas $2019 \quad$-Çevrimiçi Yayın Tarih: 04 Ara 2019
}

\section{Özet}

Hastanedeki mamografi ve standart meme görüntüleme cihazları, özellikle 40 yaş üstü ve kilolu kadınların meme kanseri teşhisi için yeterli değildir. Sintilasyon dedektör sisteminin uzaysal çözünürlüğü, nükleer tıbbi görüntüleme için son derece önemli bir parametredir. GEANT4 tabanlı çalışan GATE simülasyon programı, görüntüleme cihazlarında kullanılan farklı sintilatörlü SPECT sisteminin araştırılması için kullanıldı. Nokta kaynağın medikal görüntüsü ImageJ yazılımı ile elde edildi ve çeşitli sintilatörler için uzaysal çözünürlük ve ortalama gri değerler gibi görüntü özellikleri karşılaştırıldı. Bu araştırma, nispeten yeni bir sintilasyon malzemesi olan $\mathrm{GAGG}(\mathrm{Ce})$ için uzaysal çözünürlük değerinin, pahalı sintilatörlerden biri olan SrI'ye çok yakın olduğunu göstermektedir. $\mathrm{NaI}, \mathrm{LaBr}$ ve $\mathrm{CeBr}$ gibi sintilatörler son derece nemçeker ve istenilen şekilde ambalajlanarak kullanılması kolay olmayan malzemelerdir. Bu nedenle, GAGG(Ce), yeni tıbbi görüntüleme cihazının bir parçası olabilmesi açısından gelecek vaat etmektedir. Bu çalışma aynı zamanda anlamlı bir görüntü elde etmek için sintilatörün önünde kolimatör kullanmanın ne kadar önemli olduğunu ve tek bir blok yerine dizi sintilatörler kümesi kullanılarak görüntü kalitesinin nasıl değiştiğini de göstermektedir. GAGG(Ce) sintilasyon materyali hakkında daha önceden GEANT4 simülasyonu ile yapılmış medikal görüntüleme üzerine sunulan bir çalışma olmadığından dolayı bu araştırma verileri türünün ilk örneğidir.

\section{Anahtar Kelimeler}

Sintilasyon, Uzaysal çözünürlük, GAGG(Ce), GATE simülasyonu, Medikal görüntüleme

*Sorumlu Yazar: Nuray Yavuzkanat, nyavuzkanat@beu.edu.tr 


\section{GÍRİş}

Dünya sağlık örgütü (WHO) 2018 y1lı verilerine göre 9.6 milyon insanın kanserden dolayı öldügü ve 18.1 milyon yeni kanser vakasının tespit edildiği raporlanmıştır [1]. Tüm ölümler içerisinde yaklaşık \%17'lik kısım akciğer, meme ve kolorektal gibi üç önemli kanser tipi kaynaklıdır. Görüntüleme yoluyla tespit edilen kanser türleri arasında sadece akciğer kanseri \%13'lik bir paya sahiptir. En çok gözlenen kanser türleri cinsiyete göre değişiklik gösterse de erkeklerde akciğer kadınlarda ise meme kanseri en çok gözlenen kanser türleridir. Kanser türlerinin teşhis edilmesi için farklı tıbbi görüntüleme türleri ve teknikleri kullanılmaktadır ve bunlar teşhiste ve tedavi sırasında hayati öneme sahiptir. Günümüzde kliniklerde kullanılan görüntüleme sistemleri; sırasıyla X-ışını, US (Ultrasound), BT (Bilgisayarlı Tomografi), MRI (Manyetik Rezonans Görüntüleme), PET-SPECT (Nükleer Görüntüleme) ve mamografidir. $\mathrm{Bu}$ görüntüleme türleri arasında en hassas olanı MRI'dır ama görüntüleme maliyeti diğer türlere göre oldukça fazla olduğu için en son tercih edilen yöntemdir (mamografiye kıyasla maliyeti on kat daha fazladır) [2].

Meme kanseri, Türkiye'de kadınlarda gözlenen kanser türleri arasında en fazla ölüm oranına sahip olan kanser türüdür [3]. Ülkemizde ve dünyada bu kanser türünün teşhisinde kullanılan en yaygın yöntem Mamografi olup düşük enerjili X-1şını kullanılarak göğsün incelenmesini sağlayan görüntüleme yöntemidir. Özellikle orta yaş ve üzeri bayanlarda bu tür vakaların görülme sıklığı nedeniyle 40 yaş üstü bayanların düzenli olarak mamografi çektirmesi önerilmektedir [4]. Ancak medikal görüntüleme tekniklerinden en önemlisi olan mamografinin \%10-15 oranında kanser teşhisinde yetersiz olduğu saptanmıştır [2-5]. Kadınlarda meme yaşa bağlı olarak lifli bez dokuda farklı yoğunluk gösterir, ayrıca boyutu, şekli her kadında farklı olduğu gibi hamilelik, emzirme ve adet gibi dönemlerde de değişikliklere uğrar. Postmenopozal dönemlerde de gögüsteki yăg doku miktarı oldukça fazladır, bu da X-ışınının (mamografi) çok daha etkili olması demektir ve bunun sonucunda daha karanlık bir medikal görüntü oluşur [6]. Memedeki doku yoğunluğunun farklılığından dolayı normal gögüs dokusu ile kanserli lezyonların ayırt edilmesi mamografi ile imkansız hale gelir [6-8]. Bu durumda biyopsi gibi ikinci bir tanıya ihtiyaç duyulur ki bu hasta için çok stresli ve pahalıdır [7]. Buna ek olarak mamografi görüntülemesiyle birlikte yapılan biyopsi ile sadece \%20-30 oranında anormal doku teşhisi konulabilmektedir [9]. Ayrıca biyopsiyle dokunun kötü huylu mu yoksa iyi huylu mu olduğu da belirlenememektedir [9]. Mamografinin tek başına meme kanseri teşhisinde yetersiz olmasından ve hatalı tanı konulma oranının yüksek olmasından dolayı özellikle son yıllarda farklı yöntemlere başvurulmuştur. 
Bu farklı yöntemlerden birisi de göğsün gama ışını yardımıyla incelenebildiği Sintimamografi yöntemidir $[10,11]$. Halen üzerinde çalışmalar sürdürülen sintimamografi, dijital mamografi, PET ve SPECT türü görüntülemelerde meme kanseri teşhisi için piyasada hali hazırda düşük maliyetli, kullanışlı ve portatif bir ürün mevcut değildir.

Gama kameraların tarihsel gelişimine bakıldığında; ilk gama kamerasının 1956 yılında Hal Anger tarafından, $10 \mathrm{~cm}$ çaplı $\mathrm{NaI}(\mathrm{Tl})$ tipi sintilatör malzeme ile birlikte yedi adet PMT (foton çoğaltıcı tüp) kullanılarak geliştirilen bu görüntüleme cihazı Anger kamerası olarak adlandırılır [12,13]. Elbette o tarihlerden günümüze gelinceye kadar bu alanda teknolojik yenilikler geliştirilse de görüntü elde etme tekniği genel olarak benzerlikler içermektedir. $\mathrm{Bu}$ tür görüntüleme cihazlarında hastaya verilen radyoiztoptan gelen gama-ışıları bir kolimatörden geçirildikten sonra kolimatörün hemen arkasına monte edilmiş kristale düşürülür. Bu kristal ile birlikte kullanılan PMT ve gerekli elektronik düzenek yardımıyla elde edilen sinyaller bilgisayar ortamına aktarılır ve görüntü işleme süreçlerinden (filtreleme gibi) geçirilerek görüntü oluşturulur. Oluşturulan anlamlı görüntü radyologlar tarafindan yorumlanıp ilgili uzmana raporlanır. Gama kameraların önlerine monte edilen kolimatörlerin şekilleri, uzunlukları, delik yapıları kullanılacak olan radyoizotop tipine, görüntü oluşturma mekanizmasına göre ve teşhis edilmek istenen vücut bölgesine göre farklılık göstermektedir. Örneğin koni-huzme tipi kolimatör özellikle beyin SPECT çalışmalarında kullanılmaktadır. Tek-delikli, çok-delikli, paralel-delikli, paralel-delikli eğimli, koni-huzme, fan-huzme, genişleyen-delik aralıklı ve daralan-delik aralıklı gibi farklı amaçlar için geliştirilen farklı türlerde kolimatörler mevcuttur [13].

$\mathrm{Bu}$ çalışmada mümkün olduğu kadar düşük doz ve daha kaliteli görüntü elde etmeyi amaçlayan yeni nesil gama görüntü dedektörü tasarımı için GEANT4 tabanlı GATE simülasyon sonuçları [14] kullanılarak geliştirilen yeni simülasyon çalışmaları sunulmuştur. Ayrıca elde edilen görüntünün en önemli medikal görüntü özelliklerinden olan uzaysal çözünürlük (spatial resolution) ve ortalama gri seviye (mean grey value) değerlerine göre en ideal sintilatör malzemesinin nasıl seçildiği açıklanmıştır. Bu gama görüntüleme cihazı mümkün olduğunca hafif, portatif ve yüksek görüntü netliğine sahip olan ve özellikle meme kanserinin teşhisinde kullanılmak üzere tasarlanmıştır. Bu çalışma, GEANT4 simülasyonu ile elde edilen sonuçlar doğrultusunda tasarlanacak olan yeni nesil gama görüntüleme dedektörünün Ar-Ge çalışmasının bir ön araştırması niteliğindedir. 


\section{MATERYAL ve YÖNTEM}

\subsection{GEANT4 Tabanlı GATE Simülasyon Programında SPECT Sisteminin Tanımlanması}

GATE (GEANT4 Application for Tomographic Emission) simülasyon programında küçük boyutlarda basit bir SPECT (gama kamerası) sistemi oluşturulmuştur [15]. Bu sistemin geometrisi Şekil 1'de gösterildiği gibidir. İki aynı özelliklere sahip olan array (sıral1-dizi) şeklindeki kristaller topluluğu karşılıklı olarak konumlandırılmıştır. Altıgen şeklindeki paralel boşluklardan oluşan ve kurşun malzemeden yapılan kolimatörler açık mavi renkle gösterilmiştir. Radyoaktif nokta kaynaktan gelen radyasyonun gelme açısı uygunsa altıgen deliklerden geçerek sintilatöre ulaşabilirler ve sintilatöre ulaşabilen bu veriler medikal görüntü elde etmek için kullanılırlar. Açısı uygun olmayan radyasyonlar kurşundan yapılmış kolimatörler tarafından soğurularak sönerler. Şekil 1'de koyu mavi renkte gösterilen ince (3 mm kalınlığı olan) dikdörtgen şeklindeki geometri sintilatör malzemesine aittir.

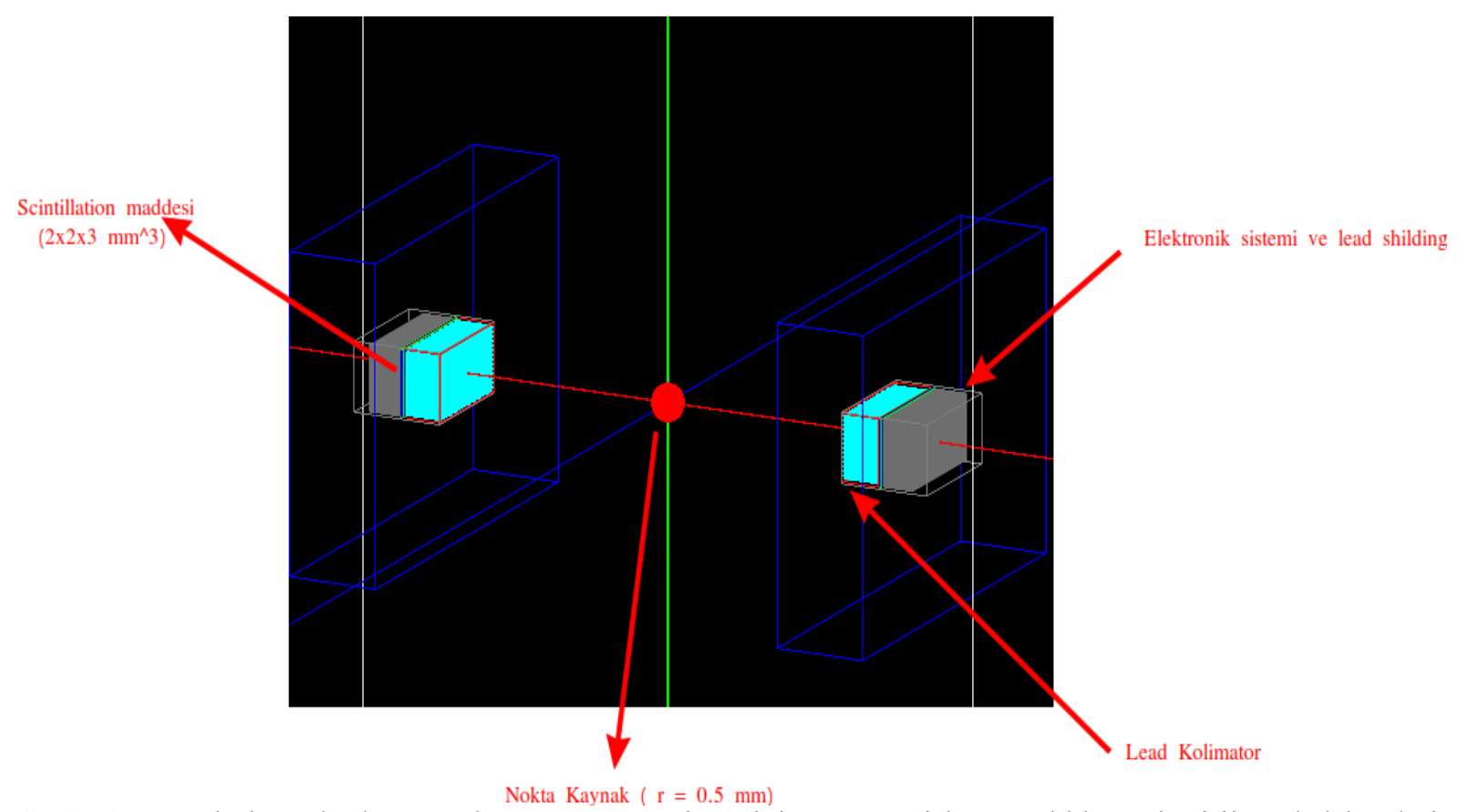

Şekil 1. Küçük boyutlarda tanımlanan SPECT sisteminin geometrisi. Karşılıklı yerleştirilen dedektörlerin merkezindeki kırmızı küre şeklindeki geometri $0.5 \mathrm{~mm}$ yarıçapında ve $140 \mathrm{keV}$ 'lik enerjiye sahip olarak tanımlanan nokta kaynağa aittir.

Sintilatörün hemen arkasında bulunan gri renkle tanımlanan geometri ise elektronik sistem için oluşturulmuştur. Her iki dedektör sistemi de kurşun malzemeden yapılan koruyucu bir zırhla kaplanmıştır. Tek altıgen-boşluklu kolimatör yapısı Şekil 2a'da, array halinde oluşturulmuş tüm kolimatör yapısı ise Şekil 2b'de gösterildiği gibidir. Tek bir altıgen boşluğun yarıçapı $0.75 \mathrm{~mm}$ ve uzunluğu $30 \mathrm{~mm}$ 'dir. Y-ekseni boyunca 14, Z-ekseni boyunca 
da 28 adet 3 mm'lik boşluklarla dikdörtgensel array (Şekil 2c) ve ikiye katlayarak doğrusal array şeklinde paralel-boşluklu kolimatör düzeneği (Şekil 2d) oluşturulmuştur.

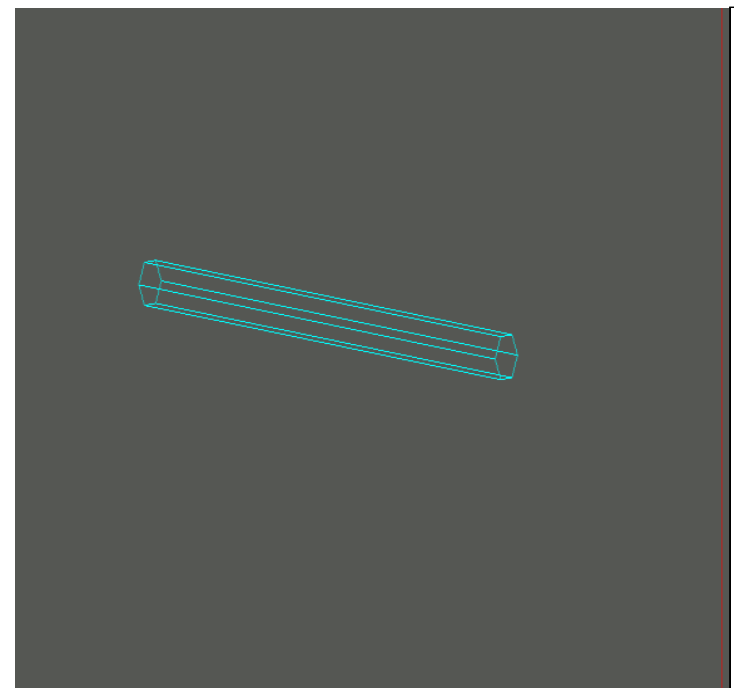

(a)

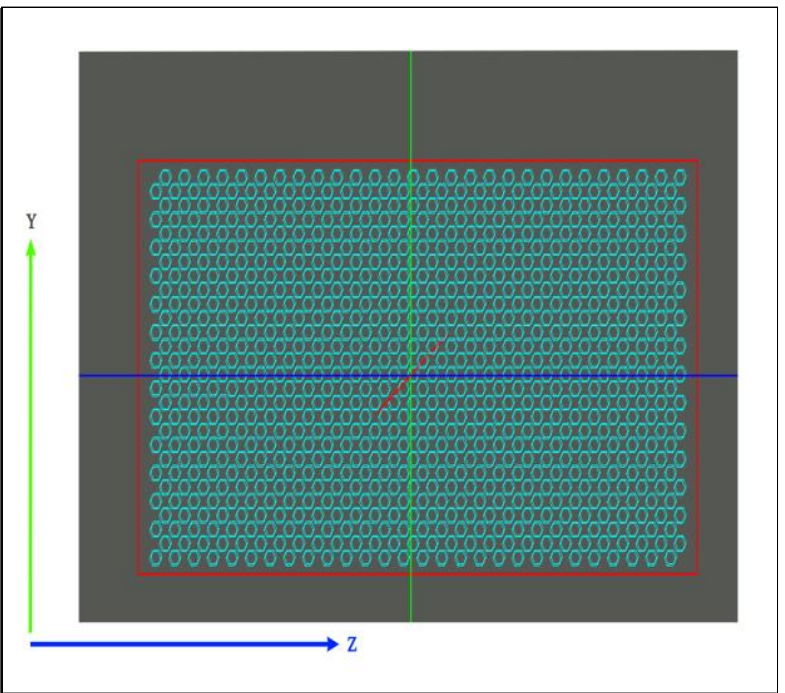

(b)

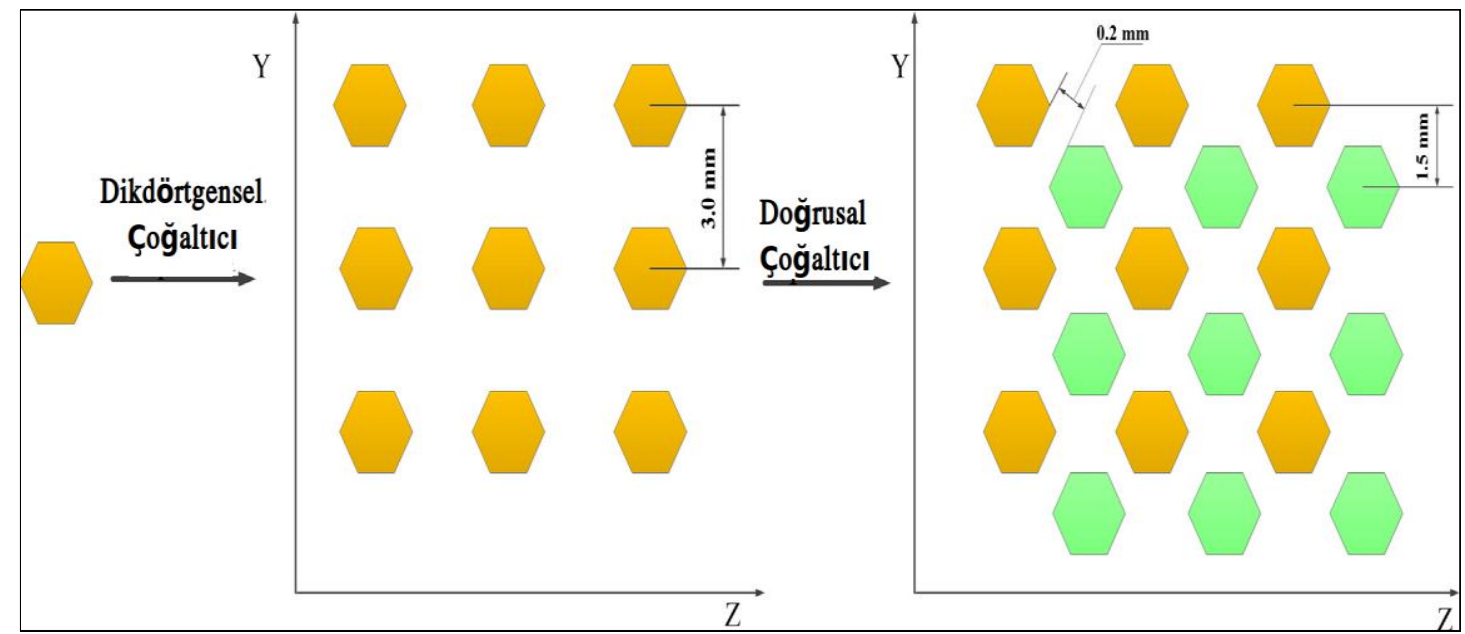

(c)

(d)

Şekil 2. Simülasyonda dikdörtgensel ve doğrusal çoğaltıcılar kullanılarak oluşturulan altıgen şeklindeki kolimatörün görüntüsü. (a) Tek altıgen-boşluklu kolimatörün gösterimi. (b) Array haline getirilen tüm kolimatörün yapısı. (c) Simülasyonda kullanılan dikdörtgensel [14] ve (d) doğrusal çoğaltıcılar [14].

Sintilasyon kristali Şekil 3'de gösterildiği gibi array halinde altıgen şekildeki kolimatörün arkasına konumlandırılmıştır ve kristal bloğunun arkasına da konum hassasiyeti olan elektronik sistem (PMTs, SiPMs (Silikon foton çoğaltıcılar) vb) yerleştirilmiştir. Elektronik sistem ve sintilasyon maddesinin karakteristik özellikleri (enerji çözünürlüğü gibi) literatürde tanımlanan değerleri bulunarak simülasyonda ayrı ayrı tanımlanmıştır [16]. 
(a)

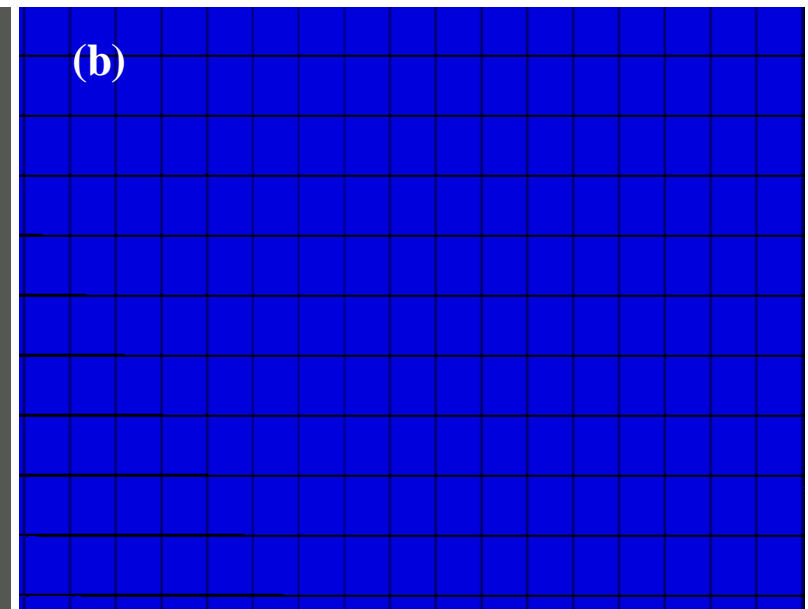

Şekil 3. (a) Tek bir sintilasyon kristalinin boyutu $2 \times 2 \times 3 \mathrm{~mm}^{3}$ 'dür. (b) Y-ekseni boyunca 22 ve $\mathrm{Z}$ ekseni boyunca da 44 adet sintilasyon maddesi lineer olarak array haline getirilmiş̧ir.

Karşılıklı konumlandırılmış birbirinin aynı iki detektör sisteminin merkezine küre şeklinde $0.5 \mathrm{~mm}$ yarıçapında, $740000 \mathrm{~Bq}$ 'lik $(0.02 \mathrm{mCi})$ aktiviteye sahip $140 \mathrm{keV}$ 'lik enerjide noktasal gama kaynağı olarak Teknesyum $\left({ }^{99 \mathrm{~m}} \mathrm{Tc}\right)$ yerleştirilmiştir. Nükleer tıbbın görüntüleme uygulamalarında yaygın olarak kullanılan Tc-99m, enjeksiyon yoluyla kana karışır ve dokularda tutunarak fizyolojik görüntü elde edilmesini sağlar. 6 saat gibi kısa yarılanma ömrüne sahip olan metastabil bir nükleer izomer olan Teknesyum'un hasta için etkin dose miktarı 8 mCi' lük aktivite için 2.4 mSv'dir [7]. Kabul edilen radyasyon risk değeri ise 50-100 $\mathrm{mSv}$ arasındadır [7]. Böylelikle hastanın maruz kalacağ 1 istenmeyen radyasyon göz ardı edilerek erken teşhisle hastanın ömrü ve yaşam kalitesinin artırılması amaçlanır. Simülasyonda sintilasyon kristalinin yüzeyi ile kaynak arasındaki mesafe $16.5 \mathrm{~cm}$ olarak sabitlenmiştir. Şekil 4'de görülen yeşil çizgiler GEANT4'da gama ışınlarını temsil etmektedirler. Her bir simülasyon sonucu için radyoaktif kaynaktan 44400000 gama 1şını yayınlanmıştır.
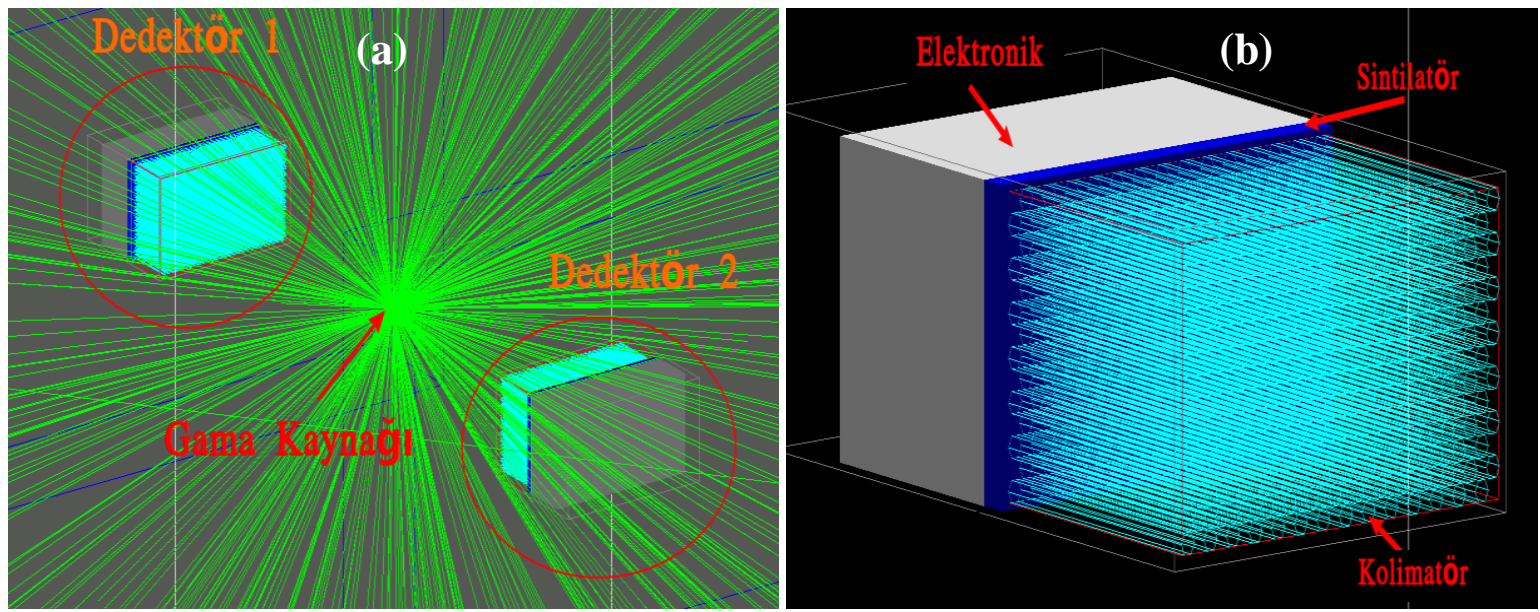

Şekil 4. (a) $0.5 \mathrm{~mm}$ yarıçapında, 740000 Bq'lik aktiviteye sahip $140 \mathrm{keV}$ ’lik enerjideki noktasal kaynaktan yayınlanan gama-1şınlarının (yeşil çizgiler) gösterimi. (b) Tek bir dedektörü oluşturan kolimatör, sintilasyon kristali ve elektronik kısımlarının yakından gösterimi. 


\section{ARAŞTIRMA BULGULARI}

GATE simülasyon programında 2 mm'lik pixel boyutlarına sahip YZ düzleminde projeksiyon görüntüsü olarak çıktılar (output dosyaları) alınmıştır. Bu çıtılar, malzeme mühendisliğinden biyolojiye kadar pek çok alanda kullanılan görüntü analiz programı "ImageJ” yardımıyla analiz edilmiştir [17]. Medikal görüntünün oluşabilmesi ya da anlamlı bir görüntü elde edilmesi için mutlaka kurşun gibi ağır metal malzemeden yapılmış bir kolimatör kullanılması gerekmektedir. Aşağıdaki şekilde kolimatör kullanmadan elde edilen YZ projeksiyon görüntüsü (Şekil 5a) ile kolimatör kullanarak oluşturulan YZ projeksiyon görüntüsü (Şekil 5b) verilmiştir. Her iki görüntü karşılaştırıldığında kolimatör kullanılarak elde edilen görüntünün anlamlı olduğu ve nokta kaynağın hatlarını daha iyi gösterdiği görülmektedir.

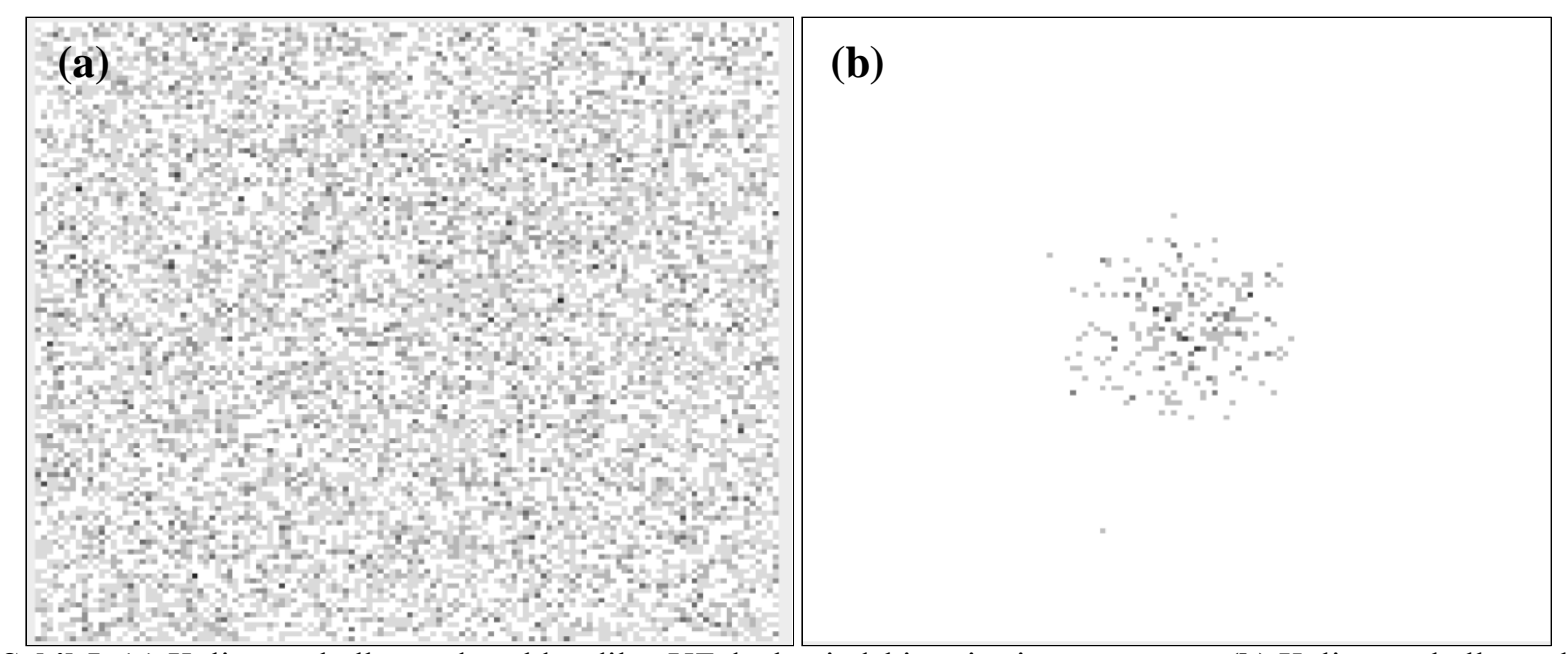

Şekil 5. (a) Kolimatör kullanmadan elde edilen YZ düzlemindeki projection görüntüsü. (b) Kolimatör kullanarak elde edilen YZ düzlemindeki projection görüntüsü.

\subsection{Uzaysal Çözünürlük (Spatial Resolution) Hesabı}

ImageJ programı kullanılarak projeksiyon görüntüsü PSF (point spread function) fonksiyonuna dönüştürülmüş ve Gaussian fonksiyonunun fit edilmesiyle yarı yükseklikteki genişlik olarak adlandırılan FWHM (Full-Width-Half-Maksimum) değerleri uzaysal çözünürlüğü ifade etmek için kullanılmıştır. LYSO sintilatörü kullanılarak elde edilen uzaysal çözünürlük hesaplamasının bir örneği Şekil 6'da gösterildiği gibidir. Bu grafikte, kırmızı noktalar projeksiyon görüntüsünün PSF fonksiyonuna dönüştürülmüş halini gösterirken, mavi çizgi ise fit edilmiş Gaussian fonksiyonunu göstermektedir. Ölçüm sistemlerinin güvenilirliğinin bir göstergesi olan FWHM değeri, Gausssian fitinden elde edilen standart sapma $(\sigma=0.71824)$ ile 2.35 sabit sayısının çarpımından elde edilir (FWHM=0.71824 x $2.35=1.6879$ ). Her bir piksel boyutunun $2 \mathrm{~mm}$ olmasından dolayı bu dedektör yapısı için uzaysal çözünürlük değeri $3.3758 \mathrm{~mm}$ olarak bulunmuştur $(1.6879$ x $2=3.3758 \mathrm{~mm})$. 


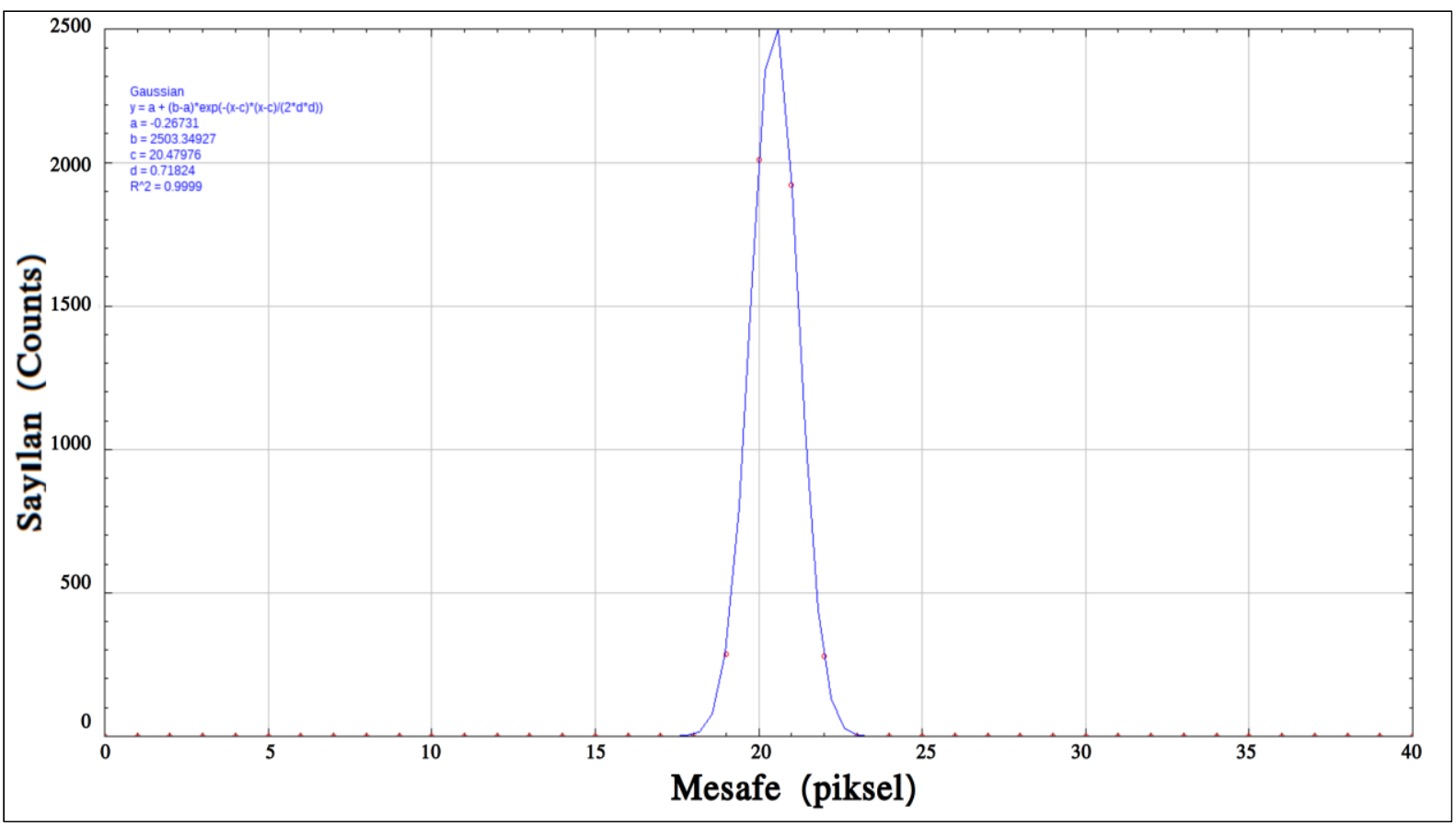

Şekil 6. Kolimatör tarafindan soğurulmadan tek bir LYSO sintilatör bloğuna ulaşabilen datalarla oluşturulan projeksion görüntüsünün ImageJ programı yardımıyla point spread fonksiyonuna çevrildikten sonra Gaussian fonksiyonu ile fit edilmiş grafiğinin gösterimi.

Tablo 1. Farklı sintilatör malzemeleriyle elde edilen noktasal kaynagın ImageJ'deki görüntülerinin uzaysal çözünürlükleri ve ortalama gri seviye değerleri.

\begin{tabular}{|c|c|c|}
\hline Sintilatör Malzemesi & $\begin{array}{c}\text { Uzaysal Çözünürlük } \\
(\mathbf{m m})\end{array}$ & Ortalama Gri Seviye $^{\mathbf{a}}$ \\
\hline LYSO & 3.391 & 9.094 \\
\hline BGO & 3.639 & 14.836 \\
\hline CsI & 4.156 & 15.039 \\
\hline NaI & 3.317 & 10.578 \\
\hline LSO & 3.466 & 18.297 \\
\hline $\left.\mathbf{L a B r}_{\mathbf{3}} \mathbf{C e}\right)$ & 3.334 & 11.43 \\
\hline $\mathbf{C e B r}_{3}$ & 3.286 & 12.875 \\
\hline $\mathbf{S r I}^{\mathbf{S}}$ & 3.149 & 14.688 \\
\hline $\mathbf{C Z T}^{\mathbf{b}}$ & 2.819 & 14.969 \\
\hline $\mathbf{G A G G}(\mathbf{C e})$ & 3.196 & 7.61 \\
\hline
\end{tabular}

áki dedektörün FWHM ortalamasıdır

${ }^{b}$ CZT sintilasyon malzemesi olmamasına rağmen günümüzde bilinen en iyi çözünürlüğe sahip yartiletken dedektör olduğundan ve daha iyi bir karşılaş̧ırma yapabilmek için CZT'nin simülasyon sonuçları da de ğerlendirmeye alınmıştır.

Farklı sintilasyon maddesi kullanılarak hesaplanan uzaysal çözünürlük değerleri Tablo 1'de verildiği gibidir. Böylelikle gama kamerası yapımında kullanılacak olan en ideal malzeme araştırılmıştır. Suying Li ve arkadaşları tarafından 440 milyon parçacık göndererek 
gerçekleştirdikleri çalışmada pixel boyutu 2 mm'lik LYSO kristali kullanılarak elde edilen uzaysal çözünürlük değeri $3.75 \mathrm{~mm}$ olarak hesaplanmıştır [14]. Bu çalışmadaki SPECT modeli ile bizim yapmış olduğumuz simülasyon çalışmasında kurulan SPECT sistemi birbiriyle benzerdir. Fakat 440 milyon yerine, bizim yayınlamış olduğumuz gama ışınının sayıs 44400000 olup elde ettiğimiz değer ise her iki dedektör için yaklaşık olarak 3.39 mm'dir. Sintilasyon malzemesi tarafından dedekte edilen gama-ışınının sayısı arttıkça FWHM'da artacağından dolayı 440 milyon ile 3.75 mm olarak bulunan bu değere yaklaşılmış olunacaktır. Elde edilen bu sonuç simülasyon için oluşturulan sistemin doğru bir şekilde çalıştığını bize göstermiştir. Bu sistem kullanılarak yeni dedektör tasarımı yapılabileceği gibi sadece sintilasyon malzemesini değiştirerek de en ideal malzemenin seçimi yapılabilecektir.

\subsection{Gri Görüntü ve Parlaklık Hassaslığı (Gri Seviye Renk Çözünürlüğü)}

Sayısal görüntünün her bir pikselinin sahip olduğu parlaklık değeri gri seviye olarak adlandırılır. Ne kadar yüksek gri seviye varsa o kadar net görüntü oluşur ve gri seviye değeri ile işlenen görüntünün ne kadar net olacağı ve yapay sınırların farklılığı hakkında bilgi edinilir. Seçilmiş olunan alandaki tüm piksellerin içinde bulunan gri değerlerin toplamının toplam piksel sayısına oranı ise bize ortalama gri seviye değerini verir. Toplam piksel sayısı her bir görüntü için, 300 x 240 pikseldir. Şekil 7'de görüldüğü gibi bariz bir şekilde görüntü kalitesi LSO dedektöründen $\mathrm{GAGG}(\mathrm{Ce})$ kristaline doğru düşmekte ve yapay sınırların netliği azalmaktadır.

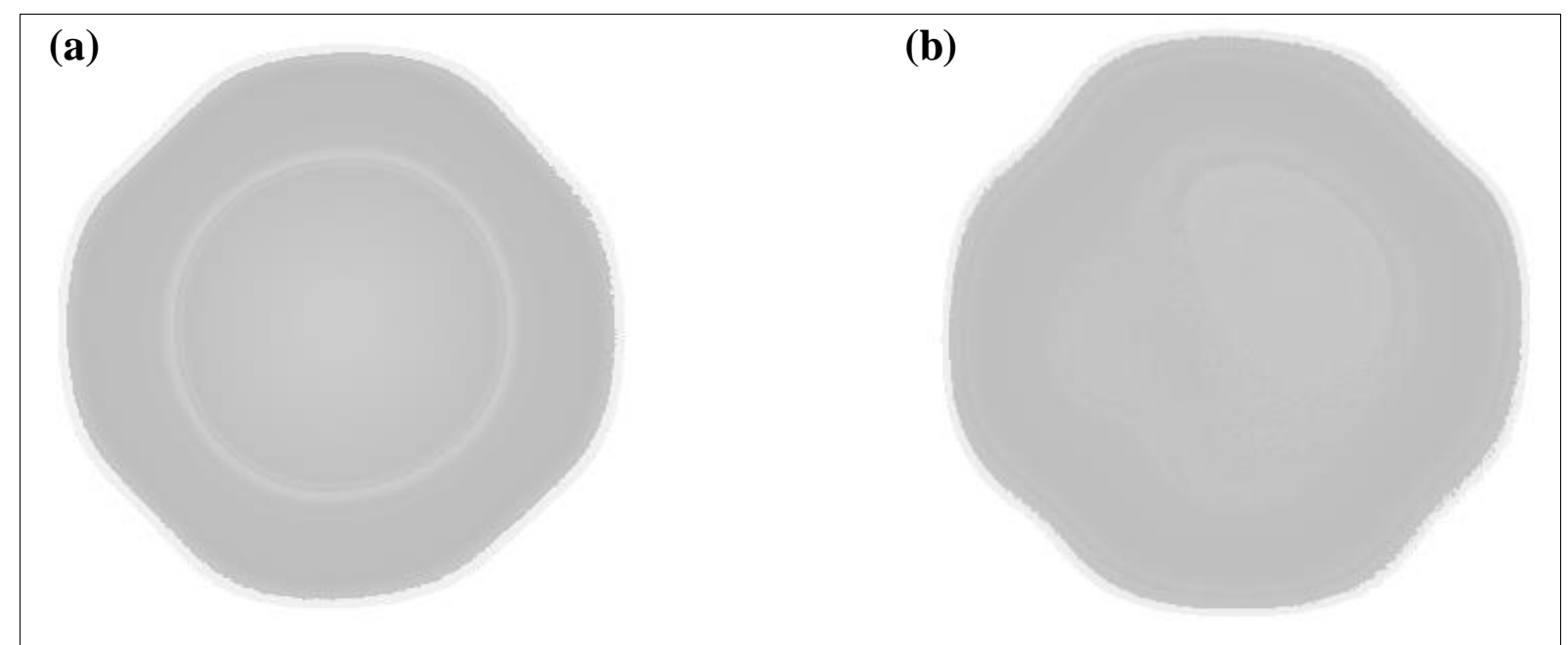

Şekil 7. (a) LSO dedektöründen elde edilen gri seviyenin görüntüsü, (b) GAGG(Ce) sintilatörü kullanılarak elde edilen gri seviye.

Eğer sintilatör malzemesini piksellere ayırmayıp tüm bir blok halinde kullanırsak elde edilen görüntü kalitesi ise oldukça düşmektedir. LYSO kristali için Şekil 8'de gösterildiği gibi uzaysal çözünürlük değeri 3.391 mm’den 9.706 mm’ye çıkmaktadır. Şekil 8a’daki görüntü, 
herbiri 2x2x3 mm³'lük hacime sahip toplam 968 kristalin bir araya gelmesiyle oluşan sintilatör malzemesi kullanılarak elde edilmiştir. Eğer sintilasyon malzemesi görüntüleme cihazında tek bir blok olarak kullanılırsa yaklaşık olarak 9.7 mm'den daha küçük lezyonların belirlenmesi zorlaşacağından dolayı, günümüzde kullanılan yeni tip görüntüleme cihazları piksellere halinde oluşturulmaktadır.
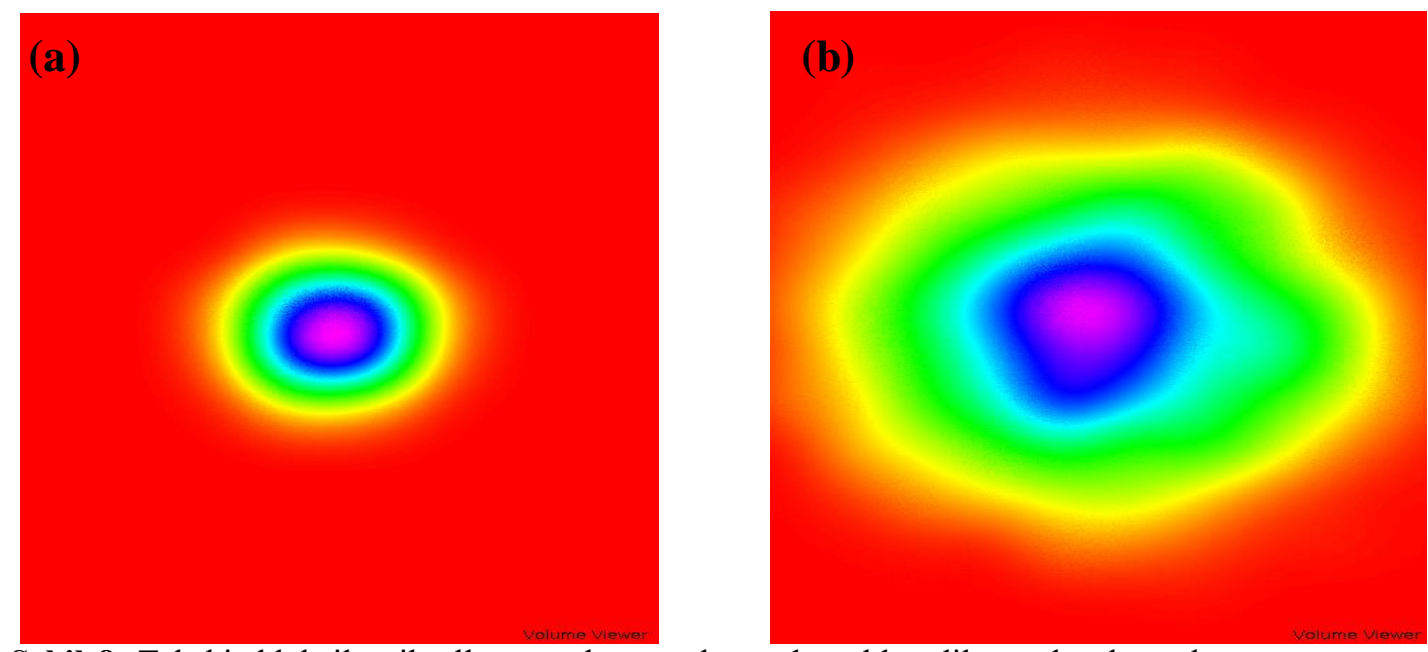

Şekil 8. Tek bir blok ile piksellere ayrılmış malzemeden elde edilen nokta kaynak görüntüsünün karşılaştırılması. (a) Array şeklindeki LYSO kristalinden elde edilen nokta kaynağın görüntüsü, (b) Tek bir blok halinde LYSO kristali kullanılarak elde edilen nokta kaynağın görüntüsü.

\section{SONUÇLAR}

Özellikle 40 yaş üstü ve kilolu kadınlarda standart olarak hastanelerde meme kanseri teşhisi için kullanılan ultrason, momografi ve X-ışını gibi cihazlarla elde edilen medikal görüntüler yeterli değildir. MRI gibi kaliteli görüntü verebilen cihazların kullanımının maliyeti ise oldukça yüksektir. Bu çalışmada yeni nesil gama görüntüleme cihazı için kullanılacak sintilatör malzemesi araştırılmıştır. GEANT4 tabanlı çalışan GATE simülasyon programı kullanılarak tanımlanan SPECT sistemindeki kristal malzemesi değiştirilerek sonuçlar bulunmuştur. İki boyutlu projeksiyon görüntüleri ImageJ programı yardımıyla analiz edilerek medikal görüntüde büyük bir öneme sahip olan uzaysal çözünürlük değerleri hesaplanmıştır. Ayrıca ortalama gri seviye değerleri de bulunmuştur. En düşük parlaklık değeri GAGG(Ce)'a ait olmasına rağmen data alma süresini artırarak veya dedektör sayısını artırarak bu değer yükseltile bilinmektedir. Bu çalışmada anlamlı bir görüntü elde edebilmek için kolimatör kullanımının nasıl bir öneme sahip olduğu görsellerle ifade edilmiştir. Ayrıca görüntü kalitesinin tek bir blok yerine piksellere ayrılmış bloklar kümesi halinde kullanıldığında ne kadar arttığ1 şekillerle gösterilmiştir. Sonuçlara göre yeni bir sintilatör olan GAGG(Ce) için bulunan uzaysal çözünürlük değeri SrI sintilatörünün değerine oldukça yakın bulunmuştur. 
Bu yüzden en ideal sintilatör malzemesi olarak GAGG(Ce) tespit edilmiştir. CZT (yarı iletken dedektörü) ve SrI (sintilatör) en pahalı dedektör sistemleri olarak hala günümüzde kullanılmaktadır. NaI, $\mathrm{CeBr}$ ve LaBr gibi sintilatörler ise nemden çok çabuk etkilendikleri ve toz halinde oldukları için ekstra bir kap içerisinde paketlenmeleri gerektiğinden istenilen şekilde paketlenmesi çok mümkün değildir. LSO ve LYSO zaten çoğu medikal görüntüleme cihazlarında yaygın olarak kullanılan sintilatörlerdir. Hedeflenen portatif, düşük maliyetli ve yüksek görüntü kalitesine sahip özellikle meme kanseri teşhisinde kullanılmak üzere geliştirilecek olan gama kamera tasarımının ön çalışması bu araştırma ile tamamlanmıştır. Ayrıca bu çalışma GAGG(Ce) sintilator malzemesi kullanılarak medikal görüntü kalitesinin araştırıldı̆̆ı ilk GEANT4 tabanlı simülasyon çalışması olması açısından da önemlidir.

\section{KAYNAKLAR}

[1] WHO, International Agency for Research on Cancer, Press Relase, No:263, 2018.

[2] M.K. O’Connor, H. Li, D.J. Rhodes, C.B. Hruska, C.B. Clancy, R.J. Vetter “Comparison of radiation exposure and associated radiation-induced cancer risks from mammography and molecular imaging of the breast", Medical Physics 37 (12):6187-6198, 2010.

[3] G. Sadikoglu, A. Ozcakır, F. Dogan, S. Gokgoz, N. Bilgel "Mammography Utilization among Turkish Women”, Asian Pacific Journal of Cancer Prevention, 11:377-381, 2010.

[4] B. D. Pettit, N. Calonge, M.L. LeFevre, B.M. Melnyk, T.J. Wilt, J.S. Schwartz "Breast Cancer Screening: Science to Recommendation", Radiology, 256(1):8-14, 2010.

[5] P. H. Niloff, N.M. Sheiner "False-negative mammograms in patients with breast cancer", CanJ Surg, 24 (50-52), 1981.

[6] M. A. Alnafea "Detection and Diagnosis of Breast Diseases", INTECH, Chapter 1, 2017.

[7] C.B. Hruska "Molecular Breast Imaging for Screening in Dense Breasts: State of the Art and Future Directions", American Journal of Roentgenology, 208(2):275-283, 2017.

[8] E. A. Sickles "Mammographic features of early breast cancer." Am J Roentgenol: 143: (461-464), 1984.

[9] F.B. Rachel, K.H. Michener, G.Zawistowski "Approaches to Improving Breast Cancer Diagnosis Using a High Resolution, Breast Specific Gamma Camera", Physica Medica, 21(1):17-21, 2006.

[10]C. Balleyguier, M. Cousin, A. Dunant, M. Attard, S. Delaloge, J. Arfi-Rouche "Patientassisted compression helps for image quality reduction dose and improves patient experience in mammography”, European Journal of Cancer, 103(137-142), 2018. 
[11]M. I. Feldman, K. Ching, C. Andaz, P. Borgen, J. Kalowitz "Breast-Specific Gamma Imaging: Early Experience, Benefits, and Challenges", Contemporary Diagnostic Radiology, 32(24):1-5, 2009.

[12]M. Demir, "Nükleer Tıp Fiziği ve Klinik Uygulamaları" Bolüm 2, İ.Ü. Cerrahpaşa Tıp Fakültesi Nükleer Tıp Anabilim Dalı Öğretim Üyesi, Pozitron Teknik Hizmetler İç ve Dış Tic. San. Ltd. Şti. 2008.

[13] I. F. Castro "Small Field of View Gamma Cameras", Doctoral Program Eng. Physics, University of Aveiro,2010.

[14]S. Li, Q. Zhang, Z. Xie, Q. Liu, B. Xu, K. Yang, C. Li, Q. Ren "GATE simulation of a LYSO-based SPECT imager: Validation and detector optimization", Nuclear Instruments and Methods in Physics Research A, 773:21-26, 2015.

[15] Open Gate Collaboration "Users Guide V8.0 From Wiki OpenGATE”. Accessed February 2018, http://www.opengatecollaboration.org/sites/default/files/GATEUsersGuideV8.0.pdf

[16] Advatech - Radiation Detection/Imaging and Photonics "Scintillation Crystals Properties". Accessed December 2018, https://www.advatech-uk.co.uk/gagg_ce.html

[17] T. Ferreira and W. Rasband, 2012. "ImageJ User Guide ImageJ/Fiji 1.46". Accessed January 20, 2018, https://imagej.nih.gov/ij/docs/guide/user-guide.pdf 